Article

\title{
Media Practices and Forced Migration: Trust Online and Offline
}

\author{
Heike Graf \\ Media and Communication Department, Södertörn University, 14104 Huddinge, Sweden; E-Mail: heike.graf@sh.se
}

Submitted: 21 November 2017 | Accepted: 28 May 2018 | Published: 29 June 2018

\begin{abstract}
This article explores the relationship between online and offline practices in the special case of forced migration. By applying a central category in social relations, trust/distrust as developed by Niklas Luhmann, this article contributes to the understanding of forced migration in the digital age. It presupposes that, without a strategy of trust, it would be almost impossible to cope with situations of unfamiliarity and uncertainty. By interviewing refugees, the question is in what contexts the refugee recognizes that they can trust (or not). The article concludes that through the combination of on- and offline communication practices, more varied mechanisms for the creation and stabilization of trust are provided. In contexts of unfamiliarity, interpersonal relations with the native inhabitants play an important role in bridging online and offline worlds.
\end{abstract}

\section{Keywords}

media technologies; migration; refugee; systems theory; trust

\section{Issue}

This article is part of the issue "Media and Communication between the Local and the Global", edited by Jessica Gustafsson (Södertörn University, Sweden) and Kinga Polynczuk-Alenius (University of Helsinki, Finland).

(C) 2018 by the author; licensee Cogitatio (Lisbon, Portugal). This article is licensed under a Creative Commons Attribution 4.0 International License (CC BY).

\section{Introduction}

When Aisha, a woman in her 40s, wakes up, she brews a cup of Arabic coffee and opens Facebook on her smartphone. She scrolls through the latest pictures posted by her daughter studying in Italy and checks her notifications to see whether she has missed a message from her husband, who has traveled to Lebanon to visit his sick father. She writes a short status update to inform her family members and friends that she is feeling well. Her family is dispersed throughout the world. None of her relatives are left in Syria, and only her sick fatherin-law could not make the journey out and is stuck in the neighboring country of Lebanon. "When I open Facebook, I feel happy, and when I don't, I close Facebook", she says. On the one hand, she is connected with her family and seems to forget that she is drinking coffee alone and living in exile. After almost four years, she still feels alienated from the country she lives in. The feeling of loneliness disappears at least for a while in the virtual realm of Facebook familiarity. On the other hand, she can control how much bad news she is willing to digest, and if the limits are reached, she leaves her Facebook feed and listens to Arabic music on YouTube and says: "I feel better". For a moment, she seems to forget troublesome news and her everyday-life in a new country that is so different from her former life, before the war, in a big house with a happy and fulfilling social life.

For Aamir, a man in his 20s, the smartphone has become his "best friend", and Dalia, in her 50s, compares her smartphone with "food". Leila, in her 40s, spends all her free time on the Internet. Rihanna, aged 25, frequently uses her smartphone, too: "I use it here for $90 \%$ of my day or maybe more. In Syria, I used it only $10 \% "$. My interviewees' smartphone use corresponds to a recent German study among refugees from Syria showing that it has considerably increased in the country of asylum compared to usage in the country they left behind (Springer, Karnowski, \& Herzer, 2016). Furthermore, in a newspaper article, a refugee claims that he trusts his smartphone "100\%" (Wall, 2015).

Based on an interview study, this article explores the relationship between online and offline communication practices in the special case of forced migration. Can we 
speak of being connected in the online world, but perhaps disconnected in the offline world? Are there any patterns evolving from online presence that indicate conditions for trust-building offline?

This article assumes that the online/offline distinction has heuristic benefits, despite the growing literature claiming a blurring of boundaries between offline and online worlds (e.g. Deuze, 2012) and arguing against a separation of online and offline realms (Boellstorff, 2012). I do not question the 'reality' of the virtual world as opposed to the 'physical' in offline worlds. Instead, I simply refer to communication with (online) or without (offline) communication technologies in order to make clear the role of media technologies for migrants' (in my case refugees') engagement in their new societies, that is, their building up of trusted relationships in a new geographical place. The relationship between geographical places, that is, the new society and virtual spaces, is of interest here. As Turkle (2011) has shown, frequent media use creates challenges in coping with both online and offline interactions.

\section{Forced Migration}

To grasp this broad and complex issue of offline/online relationships, the conditions of forced migration have to made clear. In this special case, the involvement in a nationally and culturally different place away from home is something that has been forced on people. My interviewees have described their former life (before the war) as good. As Faris in his early 30 s declares, although his parents had already emigrated, he had no intention of leaving the country: "I didn't want to leave Syria. I had a good life, went to university, had a part-time job. And I had a girlfriend. But then the war came". Even for Batoor, aged 27, the decision to leave his country was forced on him. His father and older brother were murdered by the Taliban, and as the now oldest son in his family, his mother and uncle decided to let him escape. "I was happy there, went to school and worked in my uncle's business".

Migration separates a human being from their familiar (offline) world and is often characterized by experiencing several losses, such as the loss of valued social roles, the loss of former life projects, and the loss of intimacy with beloved ones. In the new country, life is different, often involving poverty, inadequate housing conditions, unsatisfactory mastery of one's new life by, e.g., difficulties in finding a job, and problems understanding the new language and culture. The special case of exile is often described as an "unhealable rift forced between a human being and a native place" (Said, 1984, p. 49) or a "discontinuous state of being" (Hannerz, 1996, p. 105). However, especially in the digital age, although physically distant, social contacts can be retained in an effective way. What is often left of a community in a new country is the realm of the online world, that is, communicating with family members, friends, and acquaintances via social networking sites (e.g. Baldassar, 2016). Diminescu (2008) has characterized today's migrants as connected ones, characterized by multi-belongings to territories and networks.

\section{The Role of Trust}

Especially in situations of uncertainty and risk (Beck, 1986/1992) trust (as well as distrust) in people, or in information disseminated by people and organizations (offline and online) is crucial for meaning production and, more concretely, for making personal decisions such as whether to escape and whether to engage in the new society. It is assumed that, in coping with (offline) situations that are characterized by a lack of knowledge, dangers, intercultural encounters, misunderstandings, stereotypes and so on, strategies of trust and mistrust are of crucial importance. Gillespie et al. (2016) warns, for instance, that a lack of trust "drives refugees towards unofficial, potentially dangerous and exploitative resources" (Gillespie et al., 2016, p. 18). We can go further by saying that a lack of trust in general might lead to feelings of alienation (Luhmann, 2004), which in turn have an impact on the receiving society.

In other words, without a strategy of trust, it would be almost impossible to cope with situations of unfamiliarity and uncertainty. The relationship between online and offline worlds can also be described in this way: presenting oneself as perhaps approachable in the online world but unapproachable in the (new) offline world offers no opportunities for learning to build trusted relationships, and no opportunities for winning trust outside familiar online community relationships. However, social network sites can also be used for presenting oneself as approachable within the new and unfamiliar offline world, and that one places value on what is going on in the new society and shows an interest in seeking trusted relationships.

\section{Systems Theoretical Approach to Trust}

Here, I want to make use of systems theory ${ }^{1}$ as developed by the German sociologist Niklas Luhmann. His book about trust was published as early as 1968 (Vertrauen. Ein Mechanismus der Reduktion sozialer Komplexität) and 11 years later was translated into English. He relates the notion of trust to the actant, or in his words, to the "observer". The observer, in our case the refugee, acts in a context, and describes something in one way or the other way, for example whether a person or a source of information is trustworthy or not. This act of describing is what is of interest here. Or, in the

\footnotetext{
${ }^{1}$ Systems theory is basically a communication theory. To simplify, 'systems' mean a context, that is a construction of the observer, of what belongs to the context and what does not, of what is within the system and what is outside (environment). It is about marking a boundary between what is indicated and what not.
} 
words of constructivism, the reality of, for example, trustworthy information only appears to us, to the observer, through the construction/observation that an observer makes (see e.g. Fuchs, 2001).

Trust, in the broadest sense, is described by Luhmann as "confidence in one's expectations" (Luhmann, 2004, p. 4), meaning an expectation on the grounds that people and organizations, and also technologies, behave/work in accordance with one's positive expectations of them. It is the expectation that the other will handle one's vulnerability in the best way. Or, in other words, that the other will not take advantage of one's exposure. Here, trust is connected to the perspective of the observer (and not to the thing as such), from which trust is built up, maintained, or refused.

In this approach, trust is seen as a basic fact, even a precondition for social relations, and as a precondition for social life itself. It develops on an interactional field that is influenced by psychological and social contexts, including media-technological contexts, which I am especially interested in. In any trusting relationship, there are two specific parties involved: a trusting party (trustor) and a party to be trusted (trustee).

One can have trusted relations not only with individual people but also with people who are role holders, such as journalists, politicians, social workers, doctors, and so on. One can have generalized trust in institutions or organizations, such as migration departments, employment agencies, newspapers, and hospitals, and also have trust in social systems such as politics, media, and health care. Trusting these organizations means that they function at an "expected level of quality" (Blöbaum, 2016 , p. 6). It means that newspapers deliver correct information, and that migration departments decide correctly on asylum requests, and that health care works properly. Trust is also relevant within groups: refugees trust other refugees (or not); social workers trust other social workers (or not), journalists trust other journalists (or not) (Blöbaum, 2016).

However, trust is not identical to trustworthiness or the credibility of information or of people. The distinction between trust and trustworthiness can be understood in this way: the attribution of something/somebody as trustworthy refers to the observer (in our case, the refugee) on the basis of their perception. Building trust is scarcely possible without previous information that can be trusted (or not). Trustworthiness is seen as the "fundamental prerequisite for trust" (Blöbaum, 2016, p. 9) and is, therefore, not identical to trust. Here, we can find the difference between the trustworthiness of something and trust that is understood as a decision to act, and to overcome an element of uncertainty. One has decided to trust someone in order to enable possibilities of action.

Refugees' mobility is based on individual decisions to trust (or distrust) information and to trust people, organizations, and also states. A decision is based on internal (psychological system) and external (social system) fac- tors and does not mean that it has to be a rational decision or is merely a rational choice. According to Luhmann, decision is a "matter of communication" and is, therefore, a "social event" (Luhmann, 2003, p. 32). As an illustration from my interviews, Batoor says, his mother and uncle made the decision to pay the costs to let him flee. Trust means, in other words, dealing with the future in advance, by deciding to escape in order to find a secure place to live. By 'pretending' that they are confident about the future (seeking asylum in Europe), one can overcome feelings of uncertainty. For Batoor, trust in his family's decision can be seen as a kind of security, as a coping strategy in situations with uncertain futures. The same goes for his mother and uncle: in the act of communicating the decision, they are confident about making their family's survival more certain.

When one decides to trust, and therefore to act, one takes a risk. As an example, to trust this information and to choose this way and not another for an escape from one's country means taking risks. The decision to act is based on "a purely internal calculation of external conditions which creates risk" (Luhmann, as cited in Blöbaum, 2016, p. 18). First through their action the refugee becomes vulnerable, not just through trusting communication technology or other information sources. One chooses an action in preference to others in spite of the possibility of being harmed; this is, according to Luhmann, a situation of trust (Luhmann, 2000, p. 97).

More generally, risk and trust are part of a circular process. Trust is involved when a person risks something, and conversely, without risking something one cannot trust. As a consequence, exposing one's own vulnerability is the instrument for initiating relations of trust (Luhmann, 2004). Trust is only needed in uncertain and risky environments, which means when the possible harm may be greater than the advantages. Trust is not needed in a familiar world. Familiarity means in this context the 'taken for granted' character of what exists, that everything functions without risks like it used to. According to Luhmann, familiarity can be understood as "a socially constructed typicality" (Luhmann, 2004, p. 19).

In this sense, to act-on the grounds of trust-rests on motivational sources of a different nature, which in the case of refugees is their personal readiness to take great risks. Building trusted relationships on the basis of trustworthiness of information, of people, of institutions etc. is always directed towards the future, meaning a confidence in one's expectations, and a confidence in a better life elsewhere in the future. There is always the risk included that other persons or institutions can abuse one's trust.

\section{Interview Study}

In order to explore conditions for trust-building, I conducted a pilot study that consists of seven interviews with refugees in Sweden and Germany, conducted in the fall of 2017, and on studies published on refugees' me- 
dia use. All of these people interviewed, aged between 25 and 60 years, three men and four women, have received residence permits for three years in Germany or for five years in Sweden. Some were approached through snowballing, others via my volunteer work with refugees at the Red Cross. With one exception, a young man from Afghanistan, all my interviewees come from Syria. They have lived between 2.5 and 4.5 years in the new country, and currently they do not plan to return to their home countries. Two of my interviewees are unskilled (among them a housewife with a high school diploma), the others have university or college degrees. Five of them are unemployed and seeking jobs, and two have found jobs with the help of their ethnic communities. With one exception, my interviewees have some immediate family members living nearby, that is in the same city or/and the same new country. The interviewees were selected on the basis of being frequent users of the Internet, having received residence permits and studying the language of the country of asylum. In other words, they plan to settle in the new country. All my interviewees were given an alias since they were informed about ensuring informant confidentiality.

The interviews lasted between one and two hours, mostly in cafés and in two cases there were also followup interviews in private settings, that is, in the homes of the interviewees Aisha and Batoor. From these interviews especially, I gained a deeper insight in their feelings and thoughts of being a newcomer which has delivered more material for my study.

Mostly, the interviews were conducted in Swedish or English, and in two cases in Arabic with the help of an interpreter. The presence of an interpreter has made the interview more formal and therefore less rich in information. The interviews were recorded and partly transcribed. There was one exception, since it was a threehour conversational interview about almost 'all and nothing', and I only took notes. I feared that I would influence our open atmosphere in a negative way if I had put a recorder on the table.

In interviewing these people, firstly I wanted to know what they do online; second, what the interrelations between offline and online worlds look like; and finally, whether there are any patterns evolving from online presence that indicate conditions for trust-building in the offline world.

\section{Trust in the Digital Age: "Trust in Smartphones"}

When studies of trust are carried out, it is necessary to specify what type of trust is referred to. In order to relate the notion of trust to the refugee, the question must address in what contexts the refugee recognizes that they can trust (or not). As I have mentioned above, someone claims to trust their smartphone " $100 \%$ " requires looking more specifically what this can imply, which I want to explain in the following section.

\subsection{Trust in Receiving Useful and Correct Information Online}

Trust is here directed towards technical resources such as different applications. Some examples such as GPS and map functions are widely used for safely navigating journeys across land and sea. "In our group, there was always somebody who had a functioning smartphone" as Batoor relates. Locative functions are also useful in the new city, as described in the next section. Trust is also built up in other application software such as language translation programs, which all my interviewees appreciate very much. In situations of seeking a job, job-finding-applications such as "jobbrapido" and "career builder" are used that are often recommended by friends from one's own ethnic community, as my interviewees told me. Generally speaking, people tend to automatically trust sites and sources that are either recommended by people you know, or by reviews and ratings (Metzger, Flanagin, \& Medders, 2010). However, after several stereotypical responses such as "Your merits are good but there is no job for you", Aisha feels disappointed about the outcome of these job-finding applications. At the time of our last interview, she had nearly given up trusting them. Batoor tells another story about a life counseling app for managing his mental health. He has built up a trusting relationship in the performance of this product, which he says gives him valuable advice and support.

When asking my interviewees about what news platforms they use, most of them follow news programs from their home countries and also receive information through Facebook (see also Kaufmann, 2018). Swedish or German news channels are not used mostly for language reasons. They have not heard about German and Swedish public broadcasters who broadcast in simpler language especially produced for migrants. In this case, familiar news channels from the home country are prioritized. This corresponds to a study claiming that the official websites of the receiving country targeting migrants are seldom used (Felton, 2015). It applies especially to those people who generally lack trust in political and media institutions because of their experiences from their home countries (Felton, 2015).

A trusted relationship with the performance of a product means that a kind of continuity is expected, a continuity of reliable information from news channels, counseling programs, and language and map applications. Or, in the case of Aisha, who is disappointed by the outcome of some software applications, she considers no longer using them. To build up trusted relationships with new information sources is more challenging when such a relationship has not been recommended by others, or if one already has a distrustful relationship with these sources because of experiences from the past. Furthermore, trust in applications involves different levels of risk: using a job-finding-application is perhaps less risky than a locative map function when navigating a risky journey. 


\subsection{Trust in Managing the Others' Perceptions of Oneself}

A study (Kim \& Lingel, 2016) that explores newcomers in urban spaces highlights another function of smartphones besides delivering information: As a newcomer says, "I rely on mobile technology. And on avoiding having to ask some person, any person on the spot" (p. 226). This was also the case when Batoor arrived in Germany. He explains his frequent use of locative technology as follows: "I lost my confidence when I arrived in Germany". He asked a German for directions and got a very angry response: he had better leave, because there is no place for refugees. He felt surrounded by mistrust in his new context. "Now, l'd rather stick to my mobile" when asking how to get somewhere. In this case, using locative technology has the purpose of hiding one's lack of spatial knowledge and, therefore, one's status as a newcomer. A smartphone has the benefit of the user becoming 'invisible' in urban spaces, of behaving like all the other people, by paying attention to a smartphone instead of asking a stranger for directions (see also Witteborn, 2015). Furthermore, "with a smartphone, I feel normal" Batoor says. He seems to merge with the society; he does the same thing as all the other people around him. He is part of the society, and he belongs to it, at least on the surface. He feels he is managing others' perceptions of himself.

Here, the smartphone is directed at replacing the human being with a technological product that the user is familiar with, and, therefore, it seems to deliver more security in an unfamiliar environment. A smartphone cannot disappoint one's expectations, at least not in the same way. If errors occur, the consequences are not so far-reaching: one can change the battery, the application software, or the entire smartphone. One will not lose confidence in all mobile devices. To handle a loss of confidence in one's own expectations about the new country as a better place to live in is much more demanding. After 2.5 years in Germany, Batoor says, he has gradually gained his self-confidence again. However, his first interpersonal (offline) experiences have left traces which influence his behavior both in the online and offline world. If he can avoid direct contact with German people in a situation of risk and uncertainty and can replace this with an electronic device, he does that.

Acting on the basis of a decision to trust technologies also means establishing a dependent relationship with the trusted object. If, for example, a refugee trusts communication technology and takes this as a prerequisite for action, access to a phone as well to the Internet becomes vital, as described above, the smartphone is similar to "food" (Dalia) or is the "best friend" (Aamir). There are two forms of risk that can be distinguished. One of these forms relates to the anticipation that perhaps technology might not be working, or that access to the Internet or even the phone cannot be achieved. When Batoor was without his phone for two weeks because it was stolen, he borrowed a tablet from his friend to at least keep in contact with his family and to have access to his life counseling app. But during this time, he felt as "if I lost a leg. I was not complete". The other form of risk is that of replacing people, or in other words, direct contact with people, with an electronic device.

The smartphone as a multi-functional device has become an essential tool of managing social relations. Being dependent on a smartphone is a recognized phenomenon for groups other than refugees. However, perhaps, since this is in a "discontinuous state of being" (Hannerz, 1996, p. 105), smartphones seem to offer some kind of continuity and familiarity.

\subsection{Trust in People Available through Social Network} Sites

If changes in the familiar offline world occur, as with migrants, the conditions for developing trust in human relations and confidence in the new situation of the offline world are affected. Trust can be lost and has to be developed anew. The refugee lacks familiarity with the new societal context and, lacks, for instance, an understanding of the expectations of others and thus the precondition for establishing relations of trust. For example, Batoor, who "lost his confidence" when he arrived in Germany, had an expectation of the new society that everyone would welcome refugees and give them the necessary help. This also refers to an image that was popular among many refugees arriving in Germany and that is described as "positively distorted" in the study by Emmer, Richter and Kunst (2016).

In other words, for refugees, the new societal context is generally unfamiliar, but the social network sites remain the same. Familiar interpersonal connections can easily be maintained in the online world. There is a great deal of literature about how migrants in transit and destination countries can maintain "network capital" through access to the Internet (e.g. Madianou \& Miller, 2012; Georgiou, 2013; Lee \& Katz, 2015; Polson, 2016). They can easily follow information and communication from back home, can have continuous contact with their family members "where once migration has truncated it" (Baldassar, 2016, p. 156) and sustain and develop ethnic community relations with people in their country of origin as well as in their destination country. Physical proximity is no longer a precondition for the maintenance of significant social ties (see also Robertson, Wilding, \& Gifford, 2016). Digital media technologies have thus changed the mode of coping with the unfamiliar.

So, if familiarity is central "to accommodate oneself to the future in a trustful or distrustful manner" (Luhmann, 2004, p. 19), a communicative approach to the familiar online world seems to be reasonable and expected in order to cope with the new surroundings. Recent research has, for instance, shown that knowing who to trust often leads people to seek help in their own communities from those they regard as reliable sources, which is based on previous experiences. Harney (2013) notes, 
for example, that fears and uncertainties are managed by mobilizing personal online networks. In other words, the trustworthiness of the familiar online environment seems to be a of great importance in coping with the new life.

For all my interviewees, most of their Internet use is dedicated to maintaining interpersonal contacts (this is also confirmed by a study by Emmer et al., 2016), that is, mostly with friends and relatives from their home countries or with friends from their ethnic community in the new country. When asking my interviewees whether there are native inhabitants among their Facebook friends, only Dalia nods and shows me her two Swedish Facebook friends on her Facebook site. They are "very friendly employment officers", she explains. Following her new Swedish friends gives her both language training and some insights into the life of people outside her own ethnic community.

These online community structures can also promote/support the inner security or self-confidence necessary for the readiness to trust. Being active on social network sites they feel familiar with can increase personal trust, that is, trust in "in one's own selfpresentation and in other people's interpretation of it" (Luhmann, 2004, p. 40). Batoor, who reveals his loss of self-confidence, says later in the interview that he has partly regained it through his own ethnic community which he is active in. He has Twitter, Facebook and Instagram accounts where he receives recognition and approval from his community.

This corresponds to a study by Godin and Doná (2016) about young Congolese people in the UK using social media to show their knowledge in what is 'really' going on in their homeland. They become a voice in the public debate, which has helped them to gain self-confidence. These refugees find hope in social network sites and not in the physical place where they feel "stuck" (Twigt, 2017). Without hope of a better future, one loses confidence in acting in an attempt to change one's situation.

Using the familiar online world to 'recover' is an important step but must be supported by the offline world if trusted relationships are to be established. In the case of Batoor, he has received refugee status, and can attend language classes and integration courses. Now, he is able to rebuild a 'normal' life-free from merely waiting. Hence, he feels more capable of handling possible disappointments. His process of regaining self-confidence is an outcome of a learning process which is based on his motives and experiences, that is, on internal (psychological) and external (online/offline) conditions.

\section{Online-Offline Relationship}

In stressing the possibilities of Internet access for maintaining a familiar world, there are also risks attached. Scholars have, for example, interpreted massive online presence as "encapsulating" (Jansson, 2011) or as "set- tlement 'escapes'" as described in the case of young adults with refugee backgrounds in Australia (Gifford \& Wilding, 2013). The frequent use of social network sites, which, according to boyd and Ellison (2007), primarily supports pre-existing social relations rather than establishing new ones, has a special impact on migrants. This is confirmed by a recent study of Syrian refugees that concludes that "refugees feel more connected to their home than to the host community". However, they "see value in contacts with locals" which they hope to develop with the help of language apps, for instance (Springer et al., 2016).

Being included in the online world can support exclusion from social connections within the offline world. Or, in the words of Gifford and Wilding, there is a problem of: "being an insider in a virtual world ... and being an outsider in the real world" (2013, p. 569). Scholars are convinced that there is a relationship between extensive presence within the online world and integration processes in the offline world (e.g. Alencar, 2017) and that integration processes for immigrants may be delayed. However, more research is needed.

The scope for developing relations of trust and also distrust in the offline world is generally enhanced by being aware of the growing interrelation between online and offline environments, and of "a growing seamlessness of interrelations between digital and face-to-face communication" (Polson, 2015, p. 632) in meaning making in general and in building trust in particular. How to initiate trusted relations depends on the communication situation (see e.g. Smets \& Kate, 2008), and it can be assumed that risk-taking and confidence in one's own expectations are perceived differently in online and offline milieus (Blöbaum, 2016, p. 18).

A study of social media use of refugees and integration in the Netherlands (Alencar, 2017) states that social contacts offline are especially preferred when trying to obtain reliable information about important societal fields such as the labor market and education system (Alencar, 2017, p. 13). As it also has turned out in my interviews, offline contacts are essential when seeking a job, which not only includes the employment agencies, but also people who can arrange contacts with potential employers. Faris for example reveals that his dream is to work as a security officer. In order to receive reliable information, he went to the employment agency to discuss his chances. Here, in offline contacts, it seems to be easier to recognize that a person is trustworthy and can deliver reliable information. As it has turned out in my interviews and is also confirmed by the study by Emmer et al. (2016, p. 51), interpersonal information online is viewed as the most trustworthy type, and interpersonal contacts are seen as being essential for bridging offline and online worlds.

In coming into face-to face contact with locals privately, Rihanna tells that she and her husband joined an NGO initiative "Kompis Sverige" (Friend Sweden) in order to learn more about Swedish people and Swedish 
culture. "We met a nice couple. They have invited us to their house and we have invited them back. It was nice but it was already two years ago", Rihanna states. Offline contacts seem to demand more engagement from both sides and seem to make it harder to sustain a relationship. As Luhmann claims, according to the offline world: "Whoever wants to win trust must take part in social life and be in a position to build the expectations of others into his own self-presentation" (Luhmann, 2004, p. 62). This takes time and demands offline encounters which can be accompanied or even initiated by online communications.

Social network sites can also be used to present oneself as approachable in the new unfamiliar environment, not only for one's own community. I assume that social network sites can make it easier to building selfpresentation skills that tie in with the new environment, and that therefore can lower a refugee's threshold of entering a new society. However, this also implies that one knows what is going on in the new country. It was striking in my interviews that news about the new country was primarily retrieved through the filter of the subject's own community and not directly from Swedish or German news media. In the interviews, it became obvious that most of the information the interviewees were interested in and the contacts they maintain are connected to their respective home countries. Especially for those who have immediate family members in their home countries, their thoughts are often with their relatives, and the space for dealing with their new life is limited. Others, who have started a new life together with a family that is physically near and can regularly meet, seem to have better preconditions for presenting themselves as approachable within their new society. For example, Rihanna, living together with her husband and newborn son, is joining several employment programs in order to make her education more compatible with the challenges of the labor market.

\section{Conclusions: The Janus Face of the Smartphone}

Trust is, according to Luhmann, generally seen as a resource to be able to act under conditions of uncertainties and risks, and specifically as a decision to act in the light of trust or even distrust. Applying this to the conditions of today means here adding a digital, online dimension to the process of deciding to act in a trustful or distrustful manner.

On the one hand, it seems to be easier to develop relations of trust (or distrust) online. The online world connects to a familiar world and offers some kind of continuity. It makes it easier to make solid risk evaluations through easy access to knowledge and other's experiences. In other words, my interviewees have more possibilities to build trusted relationships. However, online resources are accessed selectively, and if one has learned to stay within one's own community, the scope of gaining experiences outside the community is limited.
This means, on the other hand, that certain other possibilities for trust-building can be excluded from consideration. The familiarity of the community can, therefore, also hamper trust building in an unfamiliar world. Always keeping up to date with what is going on in one's own ethnic community leaves little time for other things. Access to it is easy and distraction is, if so desired, quickly achieved. We know, based on the research literature, that technology use can "both facilitate and hamper individuals' engagement with unfamiliar environments" (Kim \& Lingel, 2016, p. 231) and can segregate and connect communication spaces.

Blöbaum (2016) claims that, under the conditions of on- and offline practices, the stabilization of trust is affected and, perhaps, its "shelf life" is reduced. Trust can easily be lost as the result of changed communication environments and has to be developed anew. This can also mean that old (dis)trusted relationships can be changed. The often-described distrust of refugees in state institutions originating from the past (Felton, 2015; Gillespie et al., 2016) is something I have not encountered in my interviews. There was, instead, a kind of disappointment expressed about employment agencies that cannot offer jobs, or about migration authorities that work too slowly. Here at least, my interviewees expected a certain level of quality and, hence, have trusted these institutions so far. It is too early, however, to speak of distrust regarding these institutions.

To summarize, through the combination of on- and offline communication practices, more varied mechanisms for the creation and stabilization of trust and even distrust can be provided. It ultimately depends on internal conditions, the motives and experiences of the refugee to use digital media technologies for buildingup trusted relationships in the offline world. However, trusted offline relationships can be supported by external conditions, that make these possibilities visible. It became obvious from the interviews that interpersonal relations, both online and offline, play an important role in seeking and maintaining trust. Hence, supporting interpersonal, meaning intercultural contacts in both the online and offline world can improve the scope of experiences of both groups, of newcomers and natives. However, it needs further research to explore under what circumstances digital communication technologies can hamper or enable engagement with the new society.

\section{Acknowledgments}

I thank my reviewers for their useful comments on an earlier version of this article.

\section{Conflict of Interests}

The author declares no conflict of interests. 


\section{References}

Alencar, A. P. (2017). Refugee integration and social media. A local and experiential perspective. Information, Communication \& Society, DOI: 10.1080/ 1369118X.2017.1340500

Baldassar, L. (2016). De-demonizing distance in mobile family lives: Co-presence, care circulation and polymedia. Global Networks, 16(2), 145-163.

Beck, U. (1992). Risk society: Towards a new modernity (Vol. 17). London: Sage. Original work published 1986

Blöbaum, B. (2016). Key factors in the process of trust. On the analysis of trust under digital conditions. In B. Blöbaum (Ed.), Trust and communication in a digitized world. Models and concepts of trust research (pp. 326). Heidelberg, New York, NY, and London: Springer.

Boellstorff, T. (2012). Rethinking digital anthropology. In H. A. Horst \& D. Miller (Eds), Digital anthropology (pp. 39-60). New York, NY: Berg.

boyd, d. m., \& Ellison, N. B. (2007). Social network sites: Definition, history, and scholarship. Journal for Computer-Mediated Communication, 13, 335-361.

Deuze, M. (2012). Media life. Cambridge: Polity.

Diminescu, D. (2008). The connected migrant: An epistemological manifesto. Social Science Information, 47, 565-579.

Emmer, M., Richter, C., \& Kunst, M. (2016). Flucht 2.0. Mediennutzung durch Flüchtlinge vor, während und nach der Flucht [Escape 2.0. Refugees' media use before, during and after the escape]. Berlin: Free University Berlin.

Felton, E. (2015). Migrants, refugees and mobility: How useful are information communication technologies in the first phase of resettlement? Journal of Technologies in Society, 11(1), 1-13.

Fuchs, S. (2001). Against essentialism. A theory of culture and society. Cambridge, MA: Harvard University Press.

Gifford, S., \& Wilding, R. (2013). Digital escapes? ICTs, settlement, and belonging among Karen Youth in Melbourne, Australia. Journal of Refugee Studies, 26(4), 558-575.

Gillespie, M., Ampofo, L., Cheesman, M., Becky, F., Iliadou, E., Issa, A., \& Skleparis, D. (2016). Mapping refugee media journeys. Smartphones and social media networks. Milton Keynes: The Open University.

Georgiou, M. (2013). Media and the city: Cosmopolitanism and difference. Cambridge: Polity.

Godin, M., \& Doná, G. (2016). "Refugee Voices", new social media and politics of representation: Young Congolese in the diaspora and beyond. Refuge: Canada's Journal on Refugees, 32(1), 60-71.

Hannerz, U. (1996). Transnational connections: Culture, people, places. London: Routledge.

Harney, N. (2013). Precarity, affect and problem solving with mobile phones by asylum seekers, refugees and migrants in Naples, Italy. Journal of Refugee Studies, 26(4), 541-557.
Jansson, A. (2011). Cosmopolitan capsules. Mediated networking and social control in expatriate spaces. In M. Christensen, A. Jansson, \& M. Christensen (Eds), Online territories: Globalization, mediated practice, and social space (pp. 239-255). New York, NY: Peter Lang.

Kaufmann, K. (2018). Navigating a new life: Syrian refugees and their smartphones in Vienna. Information, Communication \& Society, 21(6), 882-898.

Kim, H., \& Lingel, J. (2016). Working through paradoxes: Transnational migrants' urban learning tactics using locative technology. Mobile Media \& Communication, 4(2), 221-236.

Lee, S. K., \& Katz, J. E. (2015). Bounded solidarity confirmed? How Korean immigrants' mobile communication configures their social networks. Journal of Computer-Mediated Communication, 20(6), 615-631.

Luhmann, N. (2000). Familiarity, confidence, trust: Problems and alternatives. In D. Gambetta (Ed.), Trust: Making and breaking cooperative relations (pp. 94-107). Oxford: University of Oxford.

Luhmann, N. (2003). Organization. In T. Bakken \& T. Hernes (Eds), Autopoietic organization theory. Drawing on Niklas Luhmann's social systems perspective (pp. 31-52). Copenhagen: Abstrakt forlag.

Luhmann, N. (2004). Trust and power. Chichester: John Wiley \& Sons. Original work published 1968.

Madianou, M., \& Miller, D. (2012). New media and migration. London: Routledge.

Metzger, M. J., Flanagin, A. J., \& Medders, R. B. (2010). Social and heuristic approaches to credibility evaluation online. Journal of Communication, 60(3), 413-439.

Polson, E. (2015). A gateway to the global city: Mobile place-making practices by expats. New Media \& Society, 17(4), 629-645.

Polson, E. (2016). Privileged mobilities: Professional migration, geo-social media, and a new global middle class. New York, NY: Peter Lang.

Robertson, Z., Wilding, R., \& Gifford, S. (2016). Mediating the family imaginary: Young people negotiating absence in transnational refugee families. Global Networks, 16(2), 219-236.

Said, E. (1984, Spetember). The mind of winter. Reflections on life in exile. Harper's Magazine, pp. 49-55.

Smets, P., \& Kate, S. T. (2008). Let's meet! Let's exchange! LETS as an instrument for linking asylum seekers and the host community in the Netherlands. Journal of Refugee Studies, 21(3), 326-346.

Springer, N., Karnowski, V., \& Herzer, J. (2016, November 8). "I was more of a real person. Now I'm always on my smartphone". Syrian refugees' use of their mobile phones in and to manage their journey to Europe. Paper presented at the Prague Media Point, ECREA PreConference "Media and Migration", Prague, Czech Republic.

Turkle, S. (2011). Alone together: Why we expect more from technology and less from ourselves. New York, NY: Basic Books. 
Twigt, M. (2017, June). The mediation of transit. On the role of transnational affective practices within Iraqi refugee households in Jordan. Paper presented at the 67th Annual Conference of the International Communication Association, San Diego, USA.

Wall, M. (2015, September 10). No, cellphones are not a luxury for Syrian refugees. Washington Post.
Retrieved from https://www.washingtonpost.com/ news/monkey-cage/wp/2015/09/10/no-cellphonesare-not-a-luxury-for-syrian-refugees/?noredirect=on \&utm_term $=.3 f 85 d 972 c 14 f$

Witteborn, S. (2015). Becoming (im)perceptible: Forced migrants and virtual practice. Journal of Refugee Studies, 28(3), 350-367.

\section{About the Author}

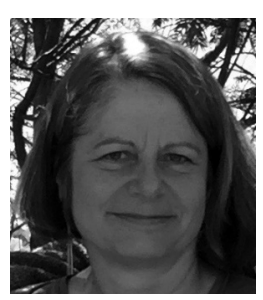

Heike Graf (PhD) is Associate Professor at the department of Media and Communication Studies, Södertörn University, Sweden. Her current research focuses on the implication of ICT on refugees' resettlement in the new country. 